\title{
The Lived Experience of Responsible Leadership: A Transcendental Phenomenological Study of Five Middle School Teachers
}

\author{
Ryan W. MacTaggart \\ Colorado State University \\ Susan A. Lynham \\ Colorado State University
}

Limited research exists at the intersection of Responsible Leadership (RL) and education organizations. The purpose of this transcendental phenomenological study was to describe the essence of a Responsible Leadership experience from the perspective of middle school teachers in the western United States. Five participants who were all active middle school educators participated in in-depth interviews about their experiences based on the 3Es of Responsible Leadership: effectiveness, ethics, and endurance. Ten shared textural descriptions of experience were constructed from the data: diligence; open RL to more people; dedication to development; take ownership; genuine care for teachers; consistency; fortitude; guided by vision and values; and desirable outcomes of $R L$ for teachers. Implications for future research and practice are addressed.

Keywords: Responsible Leadership, Transcendental Phenomenology, School Leadership, and Teacher Experience.

\section{INTRODUCTION}

Public education in the United States is an extremely large and complex system. Each day, about 248,000 schools welcome 50.4 million students into their hallways and classrooms (National Center for Education Statistics, 2018). In the next two decades, these students will become the human resource professionals of their era. They will create and run companies, develop non-profit organizations, make decisions to create or destroy employment, tackle the most complex problems in history, educate their own youth, lead the country, and engage in the affairs of the world not only US but as global ones. Due to its far-reaching influence, education offers a unique leverage point for maintaining and changing complex economic and social systems across the globe. Simply put, a systems approach recognizes that we live in webs of interdependence where actions and decisions almost never occur in isolation-what happens in our schools inevitably affects our society and world at large (Senge, 2006).

Though not often connected in academic literature, public education organizations utilize the tenants of Human Resource Development (HRD) to attain, develop, and retain teachers and other individual school leaders. For example, Bowman (2006) stated, "it is through their (principals and teachers) leadership skills, and how these skills are utilized that the school or district succeeds or fails. . Here an 
HRD practitioner would be very helpful, as individual development is an integral part of human resource development" (p. 30-3). This qualitative, phenomenological study aimed to describe the HRD principles of individual and organizational development, particularly the description of Responsible Leadership (RL) as theorized by White-Newman (1993) and Lynham (1998, 2000, 2002, 2004) in the setting of middle schools from the perspective and experience of teachers.

Leadership has been shown to be a vital component to building and maintaining beneficial systems in organizations, including those in education. The Wallace Foundation (2011), created to foster improvements in learning for disadvantaged students across the country, explained the leadership role of the principal in a school organization:

Education research shows that most school variables, considered separately, have at most small effects on learning. The real payoff comes when individual variables combine to reach critical mass. Creating the conditions under which that can occur is the job of the principal. (Wallace Foundation, 2011 as cited by National Association of Secondary School Principals [NASSP] \& National Association of Elementary School Principals [NAESP], 2013, p. 2)

Though the formal principal is important, leadership in any organization is more complex than a single person and title. According to Schmidt-Davis and Bottoms (2011), "teachers and principals working together" have more impact than principals acting alone (p. 2). Furthermore, one might argue that it is not just teachers and principals working together that makes a difference, but all stakeholders in the organizational system operating toward the common purpose of educating students amidst challenges.

School leadership systems face many demands: face-to-face and cyber bullying (Lacey \& Cornell, 2016); high proportions of student poverty (Ladd, Noguera, Reville, \& Starr, 2016); technology use and the accompanying concerns (Grinshteyn \& Yang, 2017; Jones \& Mitchell, 2016); plus general student apathy and other negative attitudes (Emmerson-Pace, 2013) that characterize many school days. Leaders also find themselves on the battlefronts of school vouchers and private versus public education (Eckes \& Mead, 2016), standardized testing (Gardner, 2000), equitable grading practices (Akins, 2017), teacher qualification and pay (DeAngelis \& Presley, 2011), and an impending teacher shortage (Sutcher, DarlingHammond, \& Carver-Thomas, 2016), to name a few. With the barrage of new opportunities and inevitable changes, organizational leadership within schools needs to be more organic and dynamic.

As school leaders seek to provide environments for academic and social-emotional success, they have a multitude of leadership options ranging from leader- to follower-focused, power- to service-focused and include (Northouse, 2016). Choosing from this plethora of options creates dilemmas - each having notable benefits and inherent drawbacks.

Responsible Leadership for Performance (RL/P) is a leadership theory that allows for the incorporation of many approaches to leadership within the complex system of education organizations. RL and RL/P have been theorized by White-Newman (1983) and Lynham (1998, 2000, 2002, 2004), respectively, using applied theory building methods (Lynham, 2000, 2002; Lynham, Taylor, Dooley, \& Naidoo, 2006). RL/P frames leadership as a system in service to an organization. Its inputs focus on Considerations of Constituency; processes of Responsibleness that are characterized by the 3Es of effectiveness, ethics, and endurance; and outputs that are Multilevel (see Lynham, 1998, 2000, 2002 for a full description of the RL/P theory).

In the spirit of beginning to study and understand RL and RL/P within the context of schools, this study focusses on the processes of RL/P, that is, Responsibleness, as constituted by the 3Es. Their nature and relevance to schools are sought to be described and better understood through this study.

Since RL/P's ingress, scholars and practitioners have conceptualized RL in various ways, pursuing meaning and better understanding of RL. Much of the related literature of the past two decades reside in business and management contexts (Maak \& Pless, 2006; Miska \& Mendenhall, 2015), ones that seldom reach across to the knowledge bases of education, the latter in which the RL/P literature resides. However, within these contexts studied, RL has been described as a system focused on serving the greater 
good and opening leadership to diverse stakeholders (Bellibas, 2015; Leech \& Fulton, 2008; Maak \& Pless, 2006), resonating well with the tenets of RL/P. So, while on the one hand the literature highlights a promising system perspective of RL (3Es) that may benefit school leadership, on the other it includes little discussion of RL's (3Es) relevance for education organizations. Furthermore, there is an absence of address of RL (3Es) from the perspective of teachers - a most important stakeholder in our organizations of education.

\section{THE PROBLEM}

The motivating problem for this study was twofold (see Figure 1), and is offered in the form of two problem syllogisms (Clark, Guskin, \& Guba, 1977) each in which two juxtaposing forces intersect to inform one problem conclusion and statement. A brief description follows.

FIGURE 1

THE DUAL PROBLEM SYLLOGISM INFORMING THE STUDY
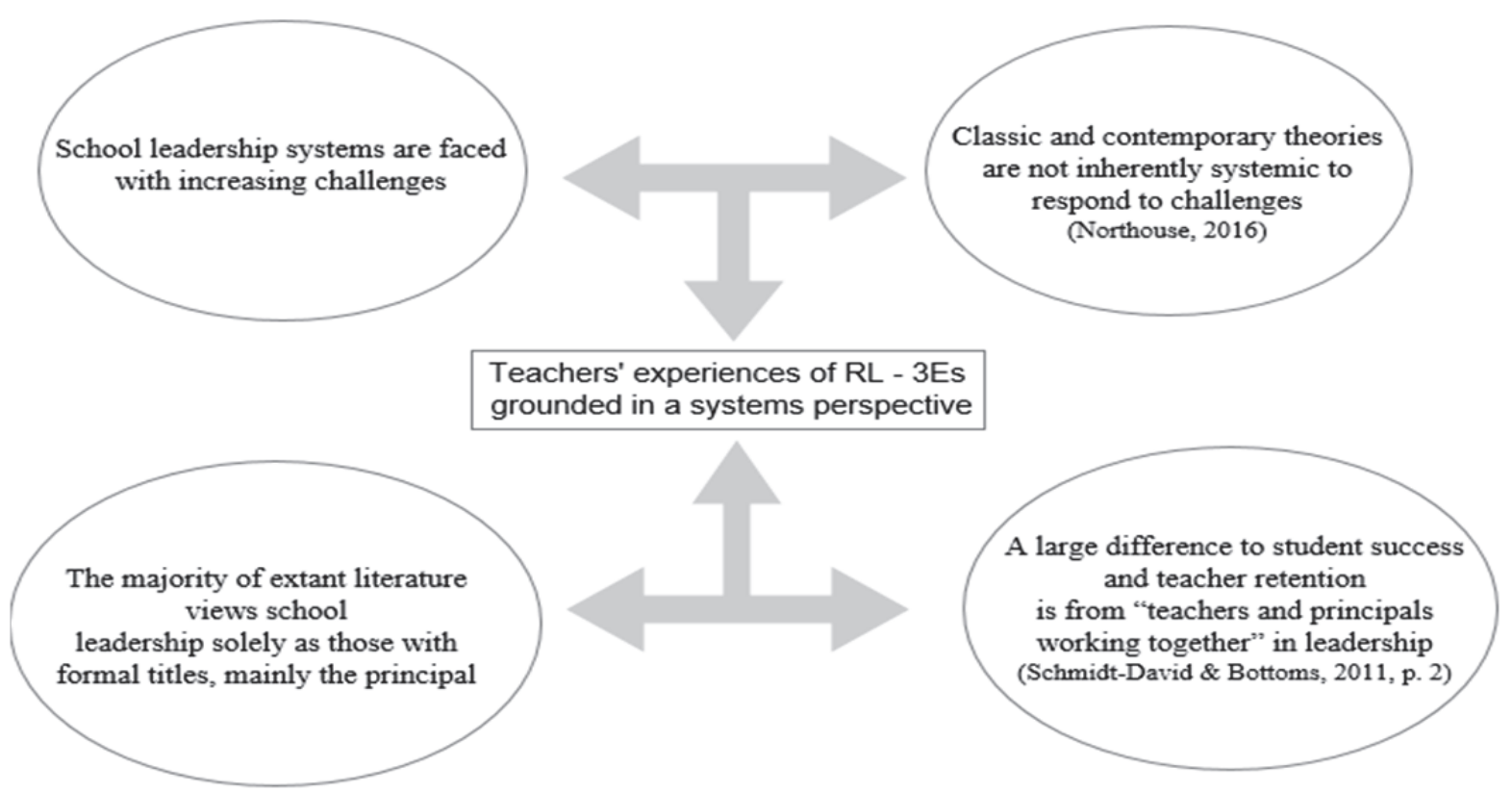

First, and on the one hand, school leadership systems are faced with increasing challenges as detailed in the introduction. Demands include student social interactions, pressures to perform on standardized testing, political battles, and an impending teacher shortage. While, on the other hand, classic and contemporary leadership approaches are not inherently systemic to respond to challenges as they often focus on leadership as a person or action (Northouse, 2016). RL and RL/P (Lynham, 1998, 2000, 2002, 2004) may offer such a system approach for leadership but has not yet been described in the context of education.

Second, and on the one hand, school leadership often references a specific person - the principal or specific teacher leaders who acts to lead, ignoring a systemic nature and approach to leadership. As a result, multiple stakeholders, processes and outcomes are inadequately explored (if at all). From this traditional conceptualization of leadership, as a single person, the needs and judgements of leadership are almost exclusively described from the perspective of those in authority positions. On the other hand (and aptly illustrated by an African proverb--Until the lion learns to write, the tale of the hunt will always glorify the hunter) (Anonymous), there is clear evidence that when additional voices within a school are heard, the tale of leadership will no longer just glorify positional power and ignore equally impactful 
stakeholders (Schmidt-Davis \& Bottoms, 2011). That when they work together, teachers and principals, multiple stakeholders in the system of the school, results are better, and more.

In response to Sutcher et al.'s (2007) call to explore the reasons behind the numbers, Burkhauser (2016) found that school leadership behavior is a highly influential variable on teacher retention. It may therefore follow that if leadership were better informed from the perspective of teachers' experiences and descriptions of effective, ethical, and enduring leadership the entire education organizational system may benefit.

\section{RESEARCH QUESTION}

To address the research problem this study aimed to construct a shared essence of teachers' lived experiences of RL (3ES) in middle schools in a United States context. One overarching research question and three sub-questions guided the study:

1. How do middle school teachers perceive and describe their experience of RL-effective, ethical, and enduring leadership — in middle schools in a western state of the United States?

\section{METHODOLGY AND METHODS}

Research is guided by an underlying set of beliefs and assumptions held by the researchers which inform what is considered to be meaningful and how to best attain it (Lincoln \& Guba, 1985, 2013). This study was rooted in the philosophical orientation of the constructivist paradigm of inquiry (Lincoln \& Guba, 1985) and executed through transcendental phenomenology (Moustakas, 1994). The constructivist paradigm guided what we valued as knowledge and shaped the research study design (Kuhn, 2012; Lincoln \& Guba, 1985). Specifically, the paradigm directs assumptions and beliefs toward subjectivist knowledge, valuing the experience of the individual as meaningful. The paradigm also guided the proper method to attain subjective experience, informing the choice of transcendental phenomenology to describe and understand the essence of lived experience through "disciplined and systematic efforts to set aside prejudgments regarding the phenomenon" (Moustakas, 1994, p. 22). We were not searching to describe RL (3Es) itself, but rather what and how participants experience RL (Moustakas, 1994), and through this shared experience come to know and understand RL (3Es) better. We were thus seeking the essence of experience through participants' own consciousness of thoughts, feelings, and sensual awareness. The method also provided the process for collecting and analyzing data.

\section{Participant Selection}

The criteria for participant selection, as outlined by Moustakas (1994), were the participant (a) had intense experience of the phenomenon, (b) was interested in understanding it, and (c) was willing to participate and have findings published. Intensity selection described by Patton (2001) was utilized to identify potential participants who manifested intense experiences of RL (3Es) as middle school teachers in the specified location. To ensure intensity, participants met multiple criteria by being: (a) in their third year of service or more in middle school sites reflecting the state policy of a teacher moving from probationary to permanent; (b) self-identified as having had experiences with effective, ethical, and enduring leadership in middle schools via email recruitment; (c) interested in the topic and finding it meaningful to their experiences; and (d) willing to partake in interviews, follow-up, and memberchecking (Moustakas, 1994).

Participants were initially contacted via email providing description of the research. Participants received a written consent form approved by a university Institutional Review Board (IRB) before data collection began. Participant identifiers were scrubbed and maintaining confidentiality was consistent with transcendental phenomenology where the aim is to understand the phenomenon in the broader context of middle schools in the study area, not in a specific school organization or leadership system (Moustakas, 1994). While the participants were diverse in terms of gender identity, their specific identifiers were scrubbed to ensure anonymity. Of the five participants three self-identified as Caucasian 
females, one as a Caucasian male, and one as a Hispanic male. The lack of racial diversity was a result of the geographic area of study where the majority of educators were of Caucasian identity. The five participants shared their occupation as middle school educators and were employed in diverse districts and schools across the study area, offering variety in contextual perspectives but singular focus on the RL phenomenon. After the fifth and final participant interview, the data reached redundancy reflecting "no new information [as] forthcoming" (Lincoln \& Guba, 1985, p. 202). Additionally, the multiple layers of analysis highlighted rich and thick data on the phenomenon, exploring the latter from multiple angles and lenses thereby seeking deep understanding of each individual experience, across their descriptions, and through the 3Es (Moustakas, 1994).

\section{Site Selection}

In accordance with constructivism, the study was conducted in the middle schools in which participants naturally operate (Lincoln \& Guba, 2013). The research sites of public middle schools in the western United States provided a logical place to seek description of the essence of the participants' experiences of RL (3Es) in two ways. Firstly, middle schools-defined as schools which educate students from sixth to eighth grade - reflect the trend in education to move from a junior high school model (grades seven through nine) to a middle school model (grades six through eight). Additionally, middle school sites in the area had a practical logic as they offered convenient geographic and knowledge access to participants and data collection due to our physical and knowledge proximity (Patton, 1990).

\section{Data Collection}

To collect rich data, Moustakas (1994) suggested an "interview protocol with broad questions that facilitate rich, vital, substantive descriptions" (p. 116). Such broad inquiries are appropriate to keep the protocol open to alterations in real-time that might help participants verbalize their experiences and enacts the constructivist paradigm to facilitate co-construction of knowledge (Lincoln \& Guba, 2013). To allow participants to explore their experiences yet remain focused on the RL phenomenon, the questions were bracketed according to the 3Es (Van Manen, 2014). A final question sought understanding through the negative case of experiencing leadership that is not responsible (Patton, 1990). Each interview lasted between 60 and 90 minutes in a location "natural to the participant"- their classroom or other school site. The goal was to balance subjective approaches to knowledge construction with detailed, rigorous analytical steps (Moustakas, 1994).

The researcher must set aside prejudgments, biases, and preconceived ideas about the phenomenon as much as possible when interacting with participants and analyzing data (Moustakas, 1994, p. 84). This kind of "fresh start" was necessary in describing the participants' experiences of RL (3Es) because the 3Es have been studied and discussed in the past. Moustakas (1994) suggested that "no position whatsoever is taken. . [and] nothing is determined in advance" (p. 84). Although, as Moustakas (1994) pointed out, some things may not be bracket-able away from ones own experience, every attempt possible was made to do so.

\section{Data Analysis}

Data were analyzed via Moustakas' (1994) three-step process including: phenomenological reduction toward textural (what) description, imaginative variation toward structural (how) description, and intuitive integration toward shared essence. Additionally, we revisited the data to analyze for the 3Es and then constructed a complete shared essence of lived experience.

Phenomenological reduction "involves a pre-reflective description of things just as they appear and a reduction to what is horizontal and thematic" (Moustakas, 1994, p. 91). To horizontalize the data we counted every statement from interview transcripts of equal value. Each interview ranged from 120 to 270 total horizon statements. Next, unique and meaningful invariant constituents of the phenomenon were found when repetitive and irrelevant horizons were removed (Moustakas, 1994, p. 97). Each participant provided 60 to 130 invariant constituents. Finally, we clustered the invariant constituents into meaning units based upon typification as described by Vaismoradi, Jones, Turunen, and Snelgrove (2016) as "the 
result of researchers' creativity during the organization of codes through giving a common meaning to a group of codes with various features" (p. 105). Resulting units represented the "core themes of the experience" (Moustakas, 1994, p. 121). Each interview resulted in 10-20 meaning units. The process was ongoing construction of knowledge and meaning. The units shifted and took shape as we examined each invariant constituent to determine its own theme, and only then would we place it within a meaning unit if it was consistent with others (Lincoln \& Guba, 1985). Once typical ideas and words had connected invariant constituents into meaning units, we labeled them to capture the participants own words and ideas. Finally, we constructed textural descriptions of the phenomenon for each participant by creating the story of the meaning units together with as much of their own words as possible to ensure their voice was maintained in the co-constructed meaning (Moustakas, 1994).

Once, phenomenological reduction was complete the next step of analysis was structural to reveal the process of "the conditions that must exist for something to appear" (Moustakas, 1994, p. 99). The goal was to seek possible meanings through imagination by varying the frame of reference and approaching the phenomenon from divergent perspectives, positions, or roles. It is the process of describing the "how/in what context" that speaks to conditions of experience (Moustakas, 2004, p. 99). The four-step process described by Moustakas (2004) was used to describe significant structures. We: (a) listened to the recorded interview again and read the transcript, (b) considered potential universal structures including time in the classroom, space and environment of the school, leadership as a construct to self, other roles the participants identified with, external experience they brought to teaching, and how many varying contexts they had worked within, (c) searched the meaning units and invariant constituent statements for exemplifications of structural themes, and (d) labeled the structural themes into categories.

Intuitive integration was the final step of analysis. For each participant, the essence of the phenomenon was captured in one coherent textural-structural description statement. Essence, according to Husserl (1937/2017), is "that which is common or universal, the condition or quality without which a thing would not be what it is" (as cited in Moustakas, 1994, p. 100). By physically laying the data cards out in meaning units, the story of essence began to form. We moved units in physical space and connected them with phrases through constructivist interaction between the participants and ourselves and we were able to member-check the integrated essence statements with participants. Upon full completion, we had an essence statement constructed for each participant's textural descriptions and bounded by their structural descriptions.

In a step beyond Moustakas' (1994) individual process, we revisited data for the 3Es. We went back to the original horizons and sorted them into categories reflective of the 3Es: effective, ethical, or enduring leadership. None of the participants clearly spoke to one of the E's at a time; instead, they intertwined them in real time, revisited initial components often, and jumped ahead at times. However, they all spoke to all 3Es as the data showed.

The final step of data analysis was completing the process again across-cases toward a shared essence of RL experience. Instead of simply combing the individual essences, we revisited the data set as a whole and completed the three-step process described above, again. An additional round of member-checking via email with participants was completed to ensure that the shared essence captured elements of their individual experiences. Through this multi-step process outlined by Moustakas (1994), teacher's experiences of RL (3Es) in middle schools in the mid-west US became clearer than in the extant literature. Capturing both what the experience is and how it exists for the individuals and the group, allows for an encompassing shared essence to inform practice, theory, and research.

\section{FINDINGS}

Findings from a phenomenological study are charged with describing both what the experience has

been and how it has been experienced. Below the shared textural descriptions provide the what, while structural descriptions provide the how RL has been experienced. 


\section{Textural (What) Descriptions of Experiencing RL}

Findings were constructed from interviews with five participants (Amber, Adam, Kate, Maxine Ann, and Keith) who were active middle school educators for three years or more at the time of study. Through the process described above, nine shared textural descriptions were constructed from 23 meaning units (see Table 1): "diligence"; "open RL to more people"; "dedication to development"; "take ownership"; genuine care for teachers"; "consistency"; "fortitude"; "guided by vision and values"; and "desirable outcomes of RL for teachers". A description was considered shared, if three or more of the participants spoke to it.

TABLE 1

SHARED MEANING UNITS AND TEXTURAL DESCRIPTIONS CONSTRUCTED ACROSS RL EXPERIENCES

\begin{tabular}{ll}
\hline \multicolumn{1}{c}{ Meaning Units } & Textural (what) Description \\
\hline $\begin{array}{l}\text { Physical presence } \\
\text { Active engagement in education }\end{array}$ & Diligence \\
\hline $\begin{array}{l}\text { Humility } \\
\text { Listening }\end{array}$ & Open RL to more people \\
Build a great team and share decisions & Dedication to development \\
\hline $\begin{array}{l}\text { Staff development } \\
\text { Personal development of leadership }\end{array}$ & Take ownership \\
\hline $\begin{array}{l}\text { Own your role - the good and bad } \\
\text { Act as a model }\end{array}$ & Genuine care for teachers \\
\hline $\begin{array}{l}\text { Be relational } \\
\text { Value teachers as people }\end{array}$ & \\
Value teachers as professionals & Consistency \\
\hline $\begin{array}{l}\text { Consistent behavior } \\
\text { Consistent treatment of others }\end{array}$ & Fortitude \\
$\begin{array}{l}\text { Courageously advance } \\
\text { Embrace difficulty and tough conversations } \\
\text { Transparency }\end{array}$ & \\
\hline $\begin{array}{l}\text { Prioritize the vision } \\
\text { Driven by deep values } \\
\text { Genuine desire for impact }\end{array}$ & Guided by vision and values \\
\hline $\begin{array}{l}\text { Feel impactful and meaningful to the cause } \\
\text { Feel heard } \\
\text { Desire to commit themselves }\end{array}$ & Desirable outcomes of RL for teachers \\
\hline
\end{tabular}

\section{Diligence}

Diligence, being careful and persistent, encapsulated participants desire for RL to be physically present throughout school and actively engaged in the broader education field. School leadership literature reflects a concern that leadership may be too involved in teachers' activities (Lee \& Nie, 2017), but participants reflected a more balanced approach to RL presence. Kate said that even though principals are busy, she always appreciated "when they are at least present" and available to her. Maxine Ann added bluntly that, "presence: being out and around in classrooms. That's important." Participants also indicated that RL practitioners should spend time in community spaces. Keith, for example, worries about "principals who always micromanage the staff," yet advised leadership to be in the hallways and other spaces. Being visible in the spaces set aside for learning is vital to RL in a school.

To be diligent, RL in schools must also be continually engaged in education at large. Most principals are "tapped into" (Myung, Loeb, \& Horng, 2011, p. 696) by their predecessors who identified potential in 
them. Though this strategy may help to identify potential RL qualities, participants indicated that commitment to active engagement with education once leaders gained formal leadership titles, was just as important. Kate thought of multiple people in her experience who moved to leadership to escape the classroom which "is super ineffective." Alternatively, Maxine Ann still held a past leader in high regard because "being able to see her at a conference in Washington, D.C. and have that connection" showed that her engagement has "endured in education beyond the job as principal." These descriptions of resulting feelings from both engaged and disengaged leadership, makes it clear that the RL is diligently dedicated to education generally and over time.

\section{Open RL to More People}

RL was also characterized as looking beyond those who hold formal leadership positions. Cheng and Szeto (2016) found that, school leadership open to "incorporating the aspirations and ideas of others" was more positive than closed leadership (p. 147). Participants shared descriptions of how to open school leadership systems through humility, listening, and building a great team for shared decisions. Kate noted, "I think [effective] leaders are willing to put aside their ego."

Humility was often described through listening. For example, Amber described her best advice for new leadership, "if I had to sum it up in one word, I would say listen." She continued, "not just listen with their ears to what people say but listen to the tone in the building and listen to what's not said and listen to the feeling from kids." Finally, participants described open leadership as teams capable of shared decisions. Adam was regularly frustrated when RL struggled to build a team. He lamented, "Put together a team. A leadership team or a disciplinary team. Come up with it. Figure something out." Leadership based on team building through humble listening was described as vital to RL in middle school organizations.

\section{Dedication to Development}

As discussed, RL has been positioned as a means to open systems. A consequence of more open leadership is a need for development (Maak \& Pless, 2006). Participants described RL through a dedication to providing staff and leadership's personal development. Commitment to outstanding education for students requires ongoing teacher development, support, and collaboration (Berebitsky, Goddard, \& Carlisle, 2014). Maxine Ann declared that one of her most effective RL experiences was when a leader "would dump money into expensive P.D., or find money for it" to ensure that teachers had resources for professional growth. Adam similarly reflected that "development empowered me to lead projects and staff meetings". RL in schools requires ongoing development and improvement.

In compliment to development, participants noted that RL could not be enacted without personal growth of leaders. Maxine Ann said, RL has "got to keep learning, keep growing, keep trying" in order to move a school forward; and Keith added, RL improves overtime only if leadership is learning because "the more you do something, the better you're going to get at it." The participants aspired to be the best teachers they could through continual development and they seemed to have the same expectation of RL.

\section{Take Ownership}

Logically following continual development, participants suggested that RL implies taking ownership of the leadership role - to bear the burdens, celebrate the triumphs, and model of expectations. RL understands the responsibility that accompanies the increased impact one may have as a formal leader (Mafora, 2013). Adam summed up ownership when he exclaimed, you "should already know. Every action that you do, I'm going to, whether I realize it or not, think about it. It's going to affect how I work for you." Participants regularly enforced that RL in a middle school is associated with understanding the impact leadership has and not hiding from mistakes. Ownership of good and bad plus the expectations for the school seems to be an RL requirement-leadership cannot hide from accountability. 


\section{Genuine Care for Teachers}

The participants expressed a similar sense of relationship depth similar to Mafora (2013) who associated RL with caring about people from the heart and with compassion. RL was described as relational and with value for teachers as people and professionals. Amber noted relatability was particularly important for new teachers who may find leadership to be "cold or intimidating" and Maxine Ann noted, that in her experience, RL was "super effective when super personable and relational." Participants also communicated a need to be valued as people. Adam stressed value when he spoke about his reaction to constructive feedback: "I won't take offense to it when I know that you care about me as a person." These five middle school teachers seemed to connect relatability to valuing teachers as people, but they also described a need to be valued professionally. Keith said that RL must "listen to people in the school and it's not just me as a teacher [or] these veteran teachers . . . Listen to the new teachers because they give you different perspectives," reflecting Cheng and Szeto's (2016) advocation that a variety of stakeholder sub-sets be meaningful. Personal and professional value seem necessary for an RL experience, so leadership can be open and humble.

\section{Consistency}

All five participants described an association of RL with consistent behavior and positive treatment of others. Adam lamented that as RL, "Even when you're not communicating, you are. When you think you're not communicating, you're communicating to me," requiring consistency in all actions. Keith advocated for consistency not only in actions but in treatment. He theorized, "People are very comfortable if they know a line. If I cross this line, this is going to happen. If I stay on this side of this line, this is what's going to happen." Consistent leadership actions and treatment of staff were important for these five teacher's descriptions of RL to complement open systems and fortitude.

\section{Fortitude}

Fortitude, having courage in adversity, is an apt label for many of the RL descriptions. Participants described courage needed to advance a school and embrace difficult conversations. Kate said that RL needed courage to "allow [teachers] to take some risks" and innovate within their classroom. Keith echoed that RL needs to be "willing to step out on the ledge and take a chance at something new" because "you probably learn more from failures than you do anything else". Such courage was also said to embrace tough conversations. "Any leader, who lacks that ability to have really hard conversations is not going to be an effective leader" because they cannot uphold expectations among the team, Kate said. Finally, Maxine Ann added, "If I had to say what's really important to me is that I think that, when possible, leaders be transparent with big decisions that impact the staff" indicating that fortitude allows leadership to be open with their team. Fortitude is necessary because it allows RL to engage in hard conversations, push a school forward, and do so in a transparent manner for the betterment of the students.

\section{Guided by Vision and Values}

Participants all described that RL could be motivated by money or prestige. Rather, RL should be driven by an organization wide vision as Cook (2014) discovered and ignited by deep values plus a genuine desire to lead. Amber conferred, leadership should remain "focused on the mission and vision of your school" by filtering all ideas through the question of, "Is part of the work you're doing part of our mission and vision?" To compliment the organizational vision, RL was described as personally motivated by deep rooted values. Maxine Ann said that RL should "know your core values and talk about them" because they "bleed into the school." Each of the participants also described RL with personal values such as honesty, integrity, humility, and follow-through. A final motivation for RL was a genuine desire for impact. Keith said, "You have to have a desire to make an impact" for the organization and Kate was adamant that "if you don't like being a teacher anymore, and you think, 'I'll just go to principal school, and then I'll be a principal,' you are 100\% missing the mark." RL seems to not be motivated by typical extrinsic drivers but instead guided by vision, values, and impact. 


\section{Desirable Outcomes of RL for Teachers}

A final textural description characterized desirable outcomes for the participants including feelings of significance and "being heard" resulting in desire to work hard and remain dedicated. It was apparent that these five participants desired to have a meaningful impact on education - a cause greater than themselves. Keith proclaimed that RL made "you look forward to coming to work . . . like you're making a difference and you matter in that school." Adam further added, "teachers have to feel like they a part of something" and RL guides them to feel that. An interesting description of RL came in the form of a tendency for participants to commit themselves more when they felt heard and valued. Maxine Ann said it plainly, RL "makes me work harder." By enacting the first eight textural descriptions, participants suggest that RL has powerful results for them personally and the school organization.

\section{Structural (How) Descriptions of RL}

Moustakas (1994) defined structures as "conditions that must exist for something to appear" (p. 99). These descriptions bounded the textural descriptions described above. Four structures were indicated across participant descriptions: time in the profession, occupational background, leadership exposure, and leadership in formal positions. First, the amount of time they spent teaching seemed less important than acknowledging that time mattered in how they experienced RL generally. Adam experienced RL as a new teacher who needed different actions and outcomes than Amber, Kate, Maxine Ann, and Keith who have each spent over a decade teaching. But all of them referenced time as an essential structural boundary for RL to be present and recognized as it allowed them to compare leadership experiences.

In addition to time teaching, participants described other occupational experiences that were foundational to their perceptions of RL. Amber, for example, described the lack of RL during some of her time teaching internationally. Kate referred to early in her career watching high turnover leadership to structure the importance of RL's endurance. Maxine Ann described her RL experiences by comparing them with her first principal in a different school district and Keith utilized his time in the Marine Corps to describe his RL experience. Reviewing past experience seemed to provide useful structure for the participant's RL experiences.

A related structure was the multiple contexts of leadership participants had been exposed to. The five seemed to indicate that to meaningfully describe RL, one must be exposed to both good and bad leadership. For example, Adam shared that he had once experienced poor leadership with "consistent lies or playing power games" that made him feel insignificant. Keith worked with a leader who was, "an authoritarian type" in contrast to RL that "puts quality people in and let them do their jobs." The juxtaposition of responsible and not responsible, allowed each participant to sharpen description.

The final structural description was an association between RL and people in formal positions, including principals. School leadership literature from the teacher perspective strongly associated leadership with the principal role (Bellibas, 2015; Cook, 2014). Participants also structured descriptions around formal titles such as principal and teacher leaders. Participants bounded descriptions within the four structures to experience and delineate RL from other leadership. Throughout the participants shared textural and structural descriptions, they reference the 3Es - effective, ethical, and enduring so it was apt to revisit their data for the 3Es.

\section{Shared Associations to the 3Es}

Participants spoke at depth to each of the 3Es. Effective leadership was associated with: maintaining structures of the school; having vision and purpose; communicating clearly and consistently; being dedicated to learning and development; and being a role model. Ethical leadership included: consistency, humility, value and belief in teachers, transparency, and courage. Finally, enduring leadership was described as: lasting legacy, sustained dedication to education, vision and purpose, courage, and actualizing effectiveness and ethics.

Perhaps one of the more interesting findings regarding the framework was the reciprocity among the 3Es. Maxine Ann reflected, "If you're effective, you're probably going to be enduring . . . and probably 
ethical, too, because I'm not sure you can be one without the other." For Adam, all 3Es shared a sense of required reflection, signifying a shared nature of the 3Es themselves. In describing enduring leadership, Amber had a similar insight, "It [enduring leadership] not only has to do with someone being somewhere over a period of time, but them staying effective and ethical over that period of time." It would seem that these five participants, discovered the same as Lynham (1998, 2000, 2002, 2004) had: while the 3Es are distinct descriptors of responsibleness in leadership they operate holographically to enact the processes for RL.

\section{Shared Essence (Statements)}

Moustakas (1994) described the final analysis as a "complete description of the meanings and essences of the experience, representing the group as a whole" (p. 121). The essence, visualized in Figure 2 , of the five middle school teachers allowed exploration of what participants perceived as their experiences of RL, how they structured the experiences, all guided by the 3 Es.

\section{FIGURE 2}

\section{COMPONENTS OF THE SHARED ESSENCE OF PARTICIPANT DESCRIPTIONS OF RL}

- Diligence

- Open RL to more people

- Dedication to development

- Take ownership

- Genuine care for teachers

- Consistency

- Fortitude

- Guided by values and vision

- Desirable outcomes of RL for teachers

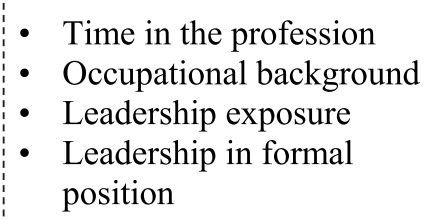

- Time in the profession

- Occupational background

- Leadership exposure

- Leadership in formal position
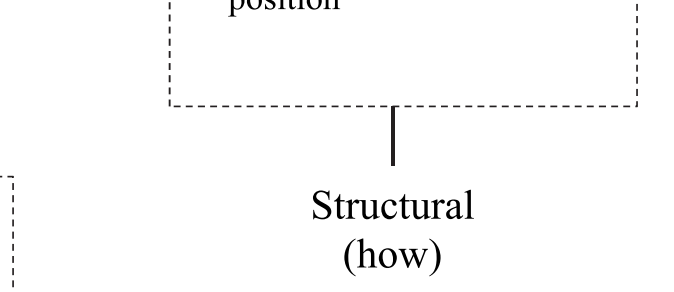

The final finding of the study is presented as a statement of essence of the lived experience of RL:

RL and those in formal leadership positions are imperative to a school. Effective RL should be motivated by a priority for making impact and a shared school-wide vision driven by commitment to ongoing staff and leadership development. Effective and ethical RL upholds teachers as professionals with significant voices and people with meaningful relationships. RL requires owning the burdens of leadership and modeling the way through dedication for active engagement in education and physical
- Maintain structures of the school

$\circ$ Have the vision and purpose

- Always communicate clearly

- Be the model

- Dedication to learning and development

- Ethical

○ Consistency

○ Humility

- Values and believe in staff

- Transparency

o Courage

- Enduring

○ Lasting legacy

- Dedication to education

- Have vision and purpose

- Courage
- Effective 
presence. To be an ethical model, RL must be: reflective, embracing of tough conversations, honest and transparent, plus courageous to advance while acting and treating others consistently. RL requires a strong team and shared decision making through humility and listening. Teachers in RL feel valued, impactful, heard, and crucial to the broader purpose of the school. When effectiveness and ethics work together, RL can endure and put lasting systems in place for the school to thrive into the future.

\section{DISCUSSION AND RECOMMENDATIONS}

The findings of this study add to the current research on RL from a previously unacknowledged constituent group. Models of RL to date have not agreed on a single definition or set of RL features. This study indicates that within the given context, RL/P is a complex system of meaningful stakeholders including teachers, parents, formal leaders, and the community. Participants suggested much as to what $\mathrm{RL}$ is - the nine textural descriptions - and how RL is structured - the four structural descriptions. To put the descriptions into action will require more research but shows promising to elevate leadership to new heights. It was also suggested that the outputs of enacted RL are positive and dynamic, but further work is needed to define outputs specifically. This study seemed to spark conversation for future research on RL, the theory of RL/P and the practice of system leadership.

Implications for RL research are three-fold. First, the thick and rich description of RL from participants who had previously not encountered the construct of the 3Es, seems to suggest a natural association with the construct and therefore motivation for future research to further refine and develop understanding of RL systems. Furthermore, well developed theoretical frameworks such as RL/P, seem to be of benefit to future research in order to address the sporadic understanding of the construct to date. Using strong theoretical groundings also could buttress the RL/P theory for leadership systems in various HRD contexts. Third, similar research to this, that considers varying contextual factors, including participant experiences, may further refine the essence of RL and add to a shared understanding of the phenomenon. Finally, the power of the teacher perspective may indicate an importance for future RL and general leadership study to include a multitude of stakeholder's perspectives for a full description. Future research regarding RL may benefit from further refinement of the RL construct, use of strong theoretical groundings, and inclusion of further participant selection.

Implications for systems leadership practice are also noteworthy. First, it seems that traditional leadership may be reimagined as complementary leadership systems - one of systemic inputs, processes, and outputs - operating alongside traditional hierarchy. Teachers, parents, students and school leaders may be empowered with their potential to enact change in local contexts and broader hierarchies of education, maybe leading to meaningful change. Another practical implication suggests that HRD and school leadership practice could benefit one another. It could be argued that the ultimate goal of a school is one of developing human resources - students, staff, administration. As the nation's preeminent places of formal learning, incorporating HRD principles would seem appropriate and beneficial. While the focus of this study in schools might not be one of traditional HRD scholarship, its findings on leadership and systems approaches seems to indicate a strong reciprocity between the two fields. HRD practitioners and scholars may find interesting areas of study in schools while school leadership practice may gain important insight from HRD.

Future research and meaningful practice may both benefit from the implications of this work. It is supported by the most recent leadership discussion from McChrystal, Eggers, and Mangone (2018) that denies the pop-culture approaches to leadership and frames leadership as "a complex system of relationships between leaders and followers, in a particular context, that provides meaning to its members" (p. 397). The relationship explored between HRD concepts of leadership and education systems, offers a new and exciting lens to explore both fields and the general study of leadership as more complex and contextual than is often described. 


\section{ACKNOWLEDGEMENT}

The authors would like to acknowledge Dr. Heidi Frederiksen, Dr. Blanche Hughes, and Dr. Pamela Coke for their mentorship, contributions, and passion for this project. All of your dedication and work was instrumental. Thank you.

\section{REFERENCES}

Akins, J. (2017). Secondary principals' perceptions of grading and grade reporting practices. (Doctoral Dissertation). Retrieved from ProQuest Dissertations and Theses database. (UMI No. AAI10016876)

Bellibas, M. S. (2015). Principals' and teachers' perceptions of effort by principals to improve teaching and learning in Turkish middle schools. Educational Sciences: Theory \& Practice, 15(6), 14711485. https://doi.org/10.12738/estp.2016.1.0009

Berebitsky, D., Goddard, R. D., \& Carlisle, J. F. (2014). An examination of teachers' perceptions of principal support for change and teachers' collaboration and communication around literacy instruction in reading first schools. Teachers College Record, 116, 1-28. Retrieved from http://www.tcrecord.org/

Bowman, J.S. (2006). HRD Practices and Interventions: Can They Be Used in the Public Education System? Academy of Human Resource Development Conference Proceedings, 2016.

Burkhauser, S. (2016). How much do school principals matter when it comes to teacher working conditions? Educational Evaluation and Policy Analysis, 39(1), 126-145. http://dx.doi.org/10.3102/0162373716668028

Cheng, A. Y. N., \& Szeto, E. (2016). Teacher leadership development and principal facilitation: Novice teachers' perspectives. Teaching and Teacher Education, 58, 140-148. http://dx.doi.org/10.1016/j.tate.2016.05.003

Cook, J. W. (2014). Sustainable school leadership: The teachers' perspective. International Journal of Educational Leadership Preparation, 9(1), 1-17. Retrieved from https://www.learntechlib.org/j/ISSN-2155-9635/

DeAngelis, K. J., \& Presley, J. B. (2011). Teacher qualifications and school climate: Examining their interrelationship for school improvement. Leadership \& Policy in Schools, 10(1), 84-120. http://dx.doi.org/10.1080/15700761003660642

Eckes, S. E., \& Mead, J. F. (2016). Introduction: "The legal and policy issues of vouchers: Multiple perspectives on private school choice." Peabody Journal of Education, 91(4), 421-423. http://dx.doi.org/10.1080/0161956X.2016.1207430

Emmerson-Pace, C. (2013). Exploring student apathy: Adult perceptions of and responses to student motivation in a charter high school. (Doctoral Dissertation). Retrieved from ProQuest Dissertations and Theses database. (UMI No. AAI3515600)

Gardner, H. (2000). The disciplined mind: Beyond facts and standardized tests, the K-12 education that every child deserves. London, UK: Penguin Books.

Grinshteyn, E., \& Yang, Y. T. (2017). The association between electronic bullying and school absenteeism among high school students in the United States. Journal of School Health, 87(2), 142-149. http://dx.doi.org/10.1111/josh.12476

Jones, L. M., \& Mitchell, K. J. (2016). Defining and measuring youth digital citizenship. New Media \& Society, 18(9), 2063-2079. http://dx.doi.org/10.1177/1461444815577797

Kuhn, T. S. (2012). The structures of scientific revolutions (50th anniversary ed.). Chicago, IL: University of Chicago Press.

Lacey, A., \& Cornell, D. G. (2016). School administrator assessments of bullying and state- mandated testing. Journal of School Violence, 15(2), 189-212. http://dx.doi.org/10.1080/15388220.2014.971362 
Ladd, H., Noguera, P., Reville, P., \& Starr, J. (2016). Education policy should address student poverty. Education Week, 35(30), 22-23. Retrieved from http://www.edweek.org/ew/ articles/2016/05/11/student-poverty-isnt-an-excuse-its-a.html

Lee, A. N., \& Nie, Y. (2017). Teachers' perceptions of school leaders' empowering behaviours and psychological empowerment. Educational Management Administration \& Leadership, 45(2), 260-283. http://dx.doi.org/10.1177/1741143215578448

Leech, D., \& Fulton, C. R. (2008). Faculty perceptions of shared decision making and the principal's leadership behaviors in secondary schools in a large urban district. Education, 128(4), 630-644. Retrieved from http://www.projectinnovation.biz/education 2006.html

Lincoln, Y. S., \& Guba, E. G. (1985). Naturalistic inquiry. Thousand Oaks, CA: Sage.

Lincoln, Y. S., \& Guba, E. G. (2013). The constructivist credo. New York, NY: Left Coast Press.

Lynham, S.A. (2004). A theory of responsible leadership for performance: Viewing leadership as a system. In T. N. Garavan, E. Collins, M.J. Morely, R. Carbery, C. Gubbins \& L. Prendeville (Eds.), Proceedings of the Fifth UFHRD/AHRD Conference (n.p.). Limerick, Ireland: The University of Limerick. Retrieved from http://www.ahrd.org/default.asp?page=Conf_Proceedings\&DGPCrSrt=\&DGPCrPg=2

Lynham, S. A. (1998). The development and evaluation of a model of responsible leadership for performance: Beginning the journey. Human Resource Development International, 1(2), 207-220. http://dx.doi.org/doi:10.1080/13678869800000025

Lynham, S. A. (2002). The general method of theory-building research in applied disciplines. Advances in Developing Human Resources, 4(3), 221-241. http://dx.doi.org/10.1177/1523422302043002

Lynham, S. A. (2000). Theory building in the human resource development profession. Human Resource Development Quarterly, 11(2), 159-178. https://dx.doi.org/10.1002/15321096(200022)11:2<159::aid-hrdq5>3.0.co;2-e

Lynham, S. A., Taylor, R. G., Dooley, L. M., \& Naidoo, V. (2006). Corporate leadership for economic, social and political change: Principles and practices learned from South African business leaders. In W. Visser, M. McIntosh, \& C. Middleton (Eds.), Corporate Citizenship in Africa: Lessons from the Past; Paths to the Future (pp. 29-42). New York, NY: Routledge.

Maak, T., \& Pless, N. M. (2006). Responsible leadership: A relational approach. In T. Maak \& N. M. Pless (Eds.), Responsible leadership (pp. 33-53). London, UK: Routledge.

Mafora, P. (2013). Learners' and teachers' perceptions of principals' leadership in Soweto secondary schools: A social justice analysis. South African Journal of Education, 33(3), 1-15. http://doi.org/10.15700/201503070742

McChrystal, S., Eggers, J., \& Mangone, J. (2018). Leaders: Myth and reality. New York, NY: Penguin.

Miska, C., \& Mendenhall, M. E. (2015). Responsible leadership: A mapping of extant research and future directions. Journal of Business Ethics, 148(1), 117-134. http://dx.doi.org/10.1007/s10551-0152999-

Moustakas, C. (1994). Phenomenological research methods. Thousand Oaks, CA: Sage.

Myung, J., Loeb, S., \& Horn, E. (2011). Tapping the principal pipeline: Identifying talent for future school leadership in the absence of formal succession management programs. Education Administration Quarterly, 47(5), 695 - 727. http://dx.doi.org/10.1177/0013161X11406112

National Center for Education Statistics. (2018). Fast facts: Educational institutions. Retrieved from https://nces.ed.gov/fastfacts/display.asp?id=84

National Association of Secondary School Principals [NASSP] \& National Association of Elementary School Principals [NAESP]. (2013). Leadership matters: What the research says about the importance of principal leadership. Retrieved from http://www.naesp.org/sites/default/files/LeadershipMatters.pdf

Northouse, P. G. (2016). Leadership: Theory and practice (7th ed.). Los Angeles, CA: Sage.

Patton, M. Q. (1990). Qualitative evaluation and research methods. Thousand Oaks, CA: Sage.

Patton, M.Q. (2001). Qualitative Research and Evaluation Methods (2nd ed.). Thousand oaks, CA: Sage. 
Rivkin, S. (2016). Desegregation since the Coleman Report: Racial composition of schools and student learning [pdf]. Education Next, 16(2), 28-37. Retrieved from http://educationnext.org/files/ednext_XVI_2_rivkin.pdf

Schmidt-Davis, J., \& Bottoms, G. (2011). Who's next? Let's stop gambling on school performance and plan for principal succession [pdf]. Retrieved from Southern Regional Education Board website: http://www.sreb.org/sites/main/files/file- attachments/11v19_principal_succession_planning.pdf

Senge, P. M. (2006). The fifth discipline: The art \& practice of the learning organization. New York, NY: Doubleday.

Sutcher, L., Darling-Hammond, L., \& Carver-Thomas, D. (2016). A coming crisis in teaching? Teacher supply, demand, and shortages in the U.S. Palo Alto, CA: Learning Policy Institute.

Vaismoradi, M., Jones, J., Turunen, H., \& Snelgrove, S. (2016). Theme development in content analysis thematic analysis. Journal of Nursing Education and Practice, 6(5), 100-110. http://dx.doi.org/10.5430/jnep.v6n5p100

Van Manen, M. (2014). Phenomenology of practice: Meaning-giving methods in phenomenological research and writing. Walnut Creek, CA: Left Coast Press.

Wallace Foundation. (2013). The school principal as leader: Guiding schools to better teaching and learning [pdf]. Retrieved from http://www.wallacefoundation.org/knowledge- center/schoolleadership/effective-principal-leadership/Documents/The-School-Principal- as-Leader-GuidingSchools-to-Better-Teaching-and-Learning.pdf

White-Newman, J.B. (1993). The three E's of leadership: A model and metaphor for effective, ethical and enduring leadership. Unpublished manuscript. St. Paul, MN: The College of St. Catherine. 